\title{
Process Safety Management Learning Module
}

\author{
Valerie Orr, Shahzad Barghi, Ralph Buchal \\ Western University \\ rbuchal@uwo.ca
}

\begin{abstract}
An engineer's paramount duty is to protect the welfare of the public. This duty includes ensuring that technical systems are designed and operated as safely as possible. This is achieved by minimizing the risk of injury or harm to people, property and the environment. Process Safety Management (PSM) is a framework for managing process risks associated with the storage, handling and manufacturing of hazardous substances, but the general principles are not industry-specific. The ultimate goal of PSM is to prevent the occurrence of major hazard incidents for the lifetime of the process, regardless of changes in personnel, organization, or environment. In PSM, a hazard incident is the unintended release of harmful substances or energy from equipment that is meant to contain it. PSM requires organizational commitment, and active participation of all stakeholders. PSM is based on process knowledge combined with systematic hazard identification and risk analysis. Risk is a measure of the probability and severity of a hazard incident. While risk is never zero, it can be minimized by taking measures to reduce the probability of occurrence, and to limit the severity of the consequences. Measures to reduce risk include inherently safer design, improving operating procedures, safer work practices, improving maintenance procedures and process documentation, improving management of change, and planning for responding to incidents. PSM systems undergo continuous improvement by incorporating lessons from hazard incidents, measuring and auditing performance, and generally learning from experience. Western University has developed a learning module on Process Safety Management to introduce engineering students to these important concepts. The module has been developed using PowerPoint, and is fully editable by instructors to suit specific learning objectives. The module includes numerous case studies to illustrate important PSM concepts, and a library of sample quiz questions is also included.
\end{abstract}

Keywords: safety education, process safety management, learning module

\section{INTRODUCTION}

Professional Engineering is a regulated profession, and "professional engineers have a clearly defined duty to society, which is to regard the duty to public welfare as paramount, above their duties to clients or employers [1]". In fulfilling this duty, Professional Engineers must ensure that technical systems are as safe as possible, minimizing the risk of injury or harm to people, property and the environment. Despite its central importance, it is difficult to find an overarching definition or framework for safety engineering. Existing safety frameworks are typically restricted to specific domains, like workplace safety, transportation safety, process safety, etc. These frameworks contain common elements and methods that can be generalized to all domains, and the elements are described in a number of texts, e.g. [2,3,4]. Every framework includes the following aspects: defining and identifying hazards; determining risks as the product of the probability of a hazard event and the consequences of the event; and taking measures to reduce risk by reducing probabilities and consequences.

The CEAB graduate attributes also emphasize the engineer's responsibility to protect the public welfare, including health and safety [5]. Education and training in these topics must be a fundamental part of the engineering curriculum. In response to this need, Minerva Canada has led and coordinated the development of a set of learning modules in health and safety. The modules were developed by student interns at 7 partner universities, as part of a Mitacs Accelerate Cluster entitled "Bridging the Gap - Health and Safety Engineering Student Teaching Modules". These modules included several core modules, along with discipline specific modules. The modules are complementary, and are meant to be used together.

Western's contribution was to develop a module covering Process Safety Management (PSM), described in this paper. 


\section{PROCESS SAFETY MANAGEMENT}

Process Safety Management (PSM) is a term applied to a systematic, proactive safety management system to manage and reduce risks associated with loss of containment events.

Table 1. Proactive versus reactive approaches to safety.

\begin{tabular}{|l|l|}
\hline \multicolumn{1}{|c|}{ Proactive } & Reactive \\
\hline $\begin{array}{l}\text { Implementing } \\
\text { countermeasures to } \\
\text { prevent an incident }\end{array}$ & $\begin{array}{l}\text { Implementing } \\
\text { countermeasures after } \\
\text { an incident has } \\
\text { occurred }\end{array}$ \\
\hline $\begin{array}{l}\text { Perform hazard } \\
\text { analysis and risk } \\
\text { assessment }\end{array}$ & $\bullet \begin{array}{l}\text { Perform incident } \\
\text { investigation and } \\
\text { determine root cause }\end{array}$ \\
\hline $\begin{array}{l}\text { Practice inherently } \\
\text { safer design }\end{array}$ & $\bullet \begin{array}{l}\text { Design \& install } \\
\text { additional layers of } \\
\text { protection after an } \\
\text { incident }\end{array}$ \\
\hline
\end{tabular}

A loss of containment incident (LoC) occurs when a hazardous substance or energy is released outside of the equipment which is meant to contain it. In some countries the amount of substance released dictates whether the incident is reportable to the government. Also, in some countries, the amount of hazardous material contained in either equipment or at a facility can determine if implementation of PSM systems is required; e.g., Environment Canada Environmental Regulations, US OSHA PSM Rule 1910.119 [6]. Hazardous substances are defined by their reactivity, toxicity, flammability, or other dangerous properties by the Canadian Environmental Protection Act Part 8 Section 200 [7].

PSM was developed in response to several major loss of containment incidents that resulted in significant loss of life, as well as extensive property and environmental damage. PSM systems are important tools for dealing with the complexity of a process facility. Several major catastrophes demonstrate the importance of PSM and the potential consequences of dysfunctional systems.

PSM is meant to provide a systematic method of dealing with process warning signs and is not meant to replace traditional process safety elements. A properly functioning PSM system should consistently and effectively manage the process hazards throughout the entire process lifetime. Particular care must be taken for the management of change as well as developing an appropriate workforce culture. A well designed and implemented system can prevent the system from being circumvented or used in a perfunctory manner which may lull management into a sense of complacency [8]. Therefore, it must work in conjunction with existing standards of process safety, environmental compliance, product quality, Responsible Care commitments [11], as well as occupational health and safety $(\mathrm{OH} \& \mathrm{~S})$ requirements [9]. Table 2 clarifies the differences between $\mathrm{OH} \& \mathrm{~S}$ and process safety.

Table 2. Process safety compared to occupational health and safety.

\begin{tabular}{|c|c|}
\hline $\begin{array}{l}\text { OCCUPATIONAL } \\
\text { HEALTH \& SAFETY }\end{array}$ & PROCESS SAFETY \\
\hline $\begin{array}{ll}\text { - } & \text { Individual-oriented \& } \\
\text { controlled } \\
\text { - } & \text { Focused on direct } \\
\text { interaction between } \\
\text { individual and } \\
\text { equipment or } \\
\text { structures } \\
\text { - } & \text { Specific impact } \\
\text { - } & \text { Work place rules \& } \\
\text { - } & \text { safety equipment } \\
\text { Worker training \& } \\
\text { supervision }\end{array}$ & $\begin{array}{l}\text { - Cooperative } \\
\text { - Broad impact } \\
\text { - Systems } \\
\text { - Little individual control }\end{array}$ \\
\hline $\begin{array}{l}\text { Examples of Possible } \\
\text { Incidents }\end{array}$ & $\begin{array}{l}\text { Examples of Possible } \\
\text { Incidents }\end{array}$ \\
\hline $\begin{array}{ll} & \text { Fall } \\
- & \text { Spill } \\
\text { - } & \text { Electrocution } \\
\text { - } & \text { Asphyxiation } \\
\text { - Hearing Impairment } & \text { and other chronic } \\
\text { injuries } \\
\text { - } \\
\text { Minor injuries (pinch, } \\
\text { banged knee, etc.) }\end{array}$ & $\begin{array}{l}\text { - Explosion } \\
\text { - Release of hazardous } \\
\text { chemical } \\
\text { - Fire } \\
\text { - Release of hazardous } \\
\text { energy }\end{array}$ \\
\hline Examples of Safeguards & Examples of Safeguards \\
\hline $\begin{array}{ll}\text { - } & \text { Hazardous Work } \\
\text { Permits } \\
\text { - Personal Protective } \\
\text { Equipment } \\
\text { - Ventilation systems, } \\
\text { confined space entry } \\
\text { - Guardrails, equipment } \\
\text { guards }\end{array}$ & $\begin{array}{ll}\text { Design } \\
\text { - } & \text { Pressure Safety Valves } \\
\text { - } & \text { Inherently Safer Design } \\
\text { - } & \text { Equipment Interlocks } \\
\text { - } & \text { Process Alarms } \\
\text { Operations } \\
\text { - } \quad \text { Maintenance } \\
\text { - Inspections } \\
\text { - } \quad \text { Training } \\
\text { - } \quad \text { Procedures }\end{array}$ \\
\hline
\end{tabular}

PSM covers the entire lifetime of the process, not just the operational lifetime. The key process lifecycle stages include: process development; detailed design; 
construction; start-up; operation; extended shut-downs; and decommissioning. PSM scope will change during the lifetime of the process. During process development, operational procedures will not be written yet, etc. Accidents can happen at any time and adequate care should be taken to prevent them at all stages.

While many of the core principles of PSM are general, the scope is clearly defined. PSM is primarily intended for the process industries but is applicable to any site storing and handling hazardous chemicals or energy. PSM is not specifically intended to address other forms of risk in other domains.

\section{HAZARDS AND RISKS}

Risk is defined as the probability of a hazard event multiplied by the severity of the consequences. In PSM, the risks are associated with loss of containment of hazardous substances. PSM recognizes several categories of risk:

\subsection{Risks to the worker}

Risks to the worker are the usual focus of occupational health and safety. These include:

- Injury or death in the workplace

- Long term health effects for workers

- Loss of employment due to disabilities

\subsection{Risks to the public}

Risks to the public are beyond the scope of occupational health and safety since they occur outside the workplace. These risks include:

- Injury or death of members of the public

- Long term health effects on the community

- Economic effects including loss of jobs in the community

- $\quad$ Reduced standard of living

\subsection{Risks to the environment}

Harm to the environment is often not considered a safety issue. However, environmental degradation will have adverse affects on the welfare of the public. These risks include:

- Air pollution

- Greenhouse gas emissions

- Property damage

- Water pollution

- Harm to fish and wildlife

- Contamination of land

\subsection{Risks to the company}

There are direct financial risks to the company as the result of an incident. However, risk management must not be based on financial costs alone. The risks include:

- Cleanup costs

- Insurance costs

- Loss of reputation

- Lost production

- Property damage

- Lawsuits and legal costs

- $\quad$ Fines and penalties

\section{THE ELEMENTS OF PSM} [8]:

PSM systems are typically organized into four pillars

1. Commitment of management and corporate objectives to PSM.

2. Hazard assessment, including process knowledge and hazard identification.

3. Risk management such as managing change in the process and change in personnel.

4. Continuous enhancement such as furthering employee education and enhancing process knowledge.

Two of the most important features of a PSM system are participation and communication. Although PSM systems are typically designed by management, they require input from operators and commitment from corporate executives to be implemented properly

PSM systems are non-prescriptive [10]. They must be based on performance indicators to measure the success of the PSM system. Guidelines can be implemented in many ways as long as the objectives are met.

PSM systems are not created once and implemented once. They are an on-going process that involves auditing and revaluation of the management system to continually enhance the effectiveness of the PSM system.

A strong safety culture establishes a strong intolerance for any violations of safe practice in order to reinforce safety as a core value. This is achieved by providing strong leadership and direction, prioritizing process safety, providing sufficient resources, and establishing performance standards and enforcing them. Engineers should always be reinforcing the organizations' commitment to safety throughout their professional activities.

\section{PSM IN CANADA}

While no specific regulations to implement PSM in process facilities in Canada currently exist, most companies are choosing to do so as industry best practice and as more data supporting the business case for PSM 
become available. The Chemistry Industry Association of Canada (CIAC) promotes PSM as part of their Responsible Care program for their members [11].

Many companies may possess facilities in the United States that are required by law since 1994 to have a functioning PSM system, and are therefore experienced with the development and implementation of these systems. While no fines will be levied for failure to possess a functional PSM system in Canada, there are still legal requirements for all people directing work to take reasonable steps to ensure worker and public safety. In the event of a loss of containment, the criminal code of Canada states that there will be severe penalties for failing to ensure the safe operation of facilities and ensure operational integrity.

The Westray Mine Explosion in Nova Scotia in 1992 killed 26 workers who were underground at the time [12]. A public inquiry found that the mine was poorly managed, worker safety was ignored, and poor oversight by the government regulators were the causes of the worse mining disaster in Canada. A criminal case was pursued against two managers but was dropped when it became unlikely they would be convicted. This case lead to legislation making negligence leading to an incident a criminal offence.

The Bill C-45 amendment to the Criminal Code of Canada states:

217.1 Every one who undertakes, or has the authority, to direct how another person does work or performs a task is under a legal duty to take reasonable steps to prevent bodily harm to that person, or any other person, arising from that work or task. [13]

\section{THE PSM LEARNING MODULE}

The PSM learning module is meant to provide an introduction to process safety management (PSM). In a very simple sense, PSM is a framework for identifying and managing process risks. It is a type of safety management system that is specific to the process industries. The principles are relevant to all disciplines of engineering involved in a process facility and are also broadly applicable to other manufacturing industries. The ultimate goal of PSM is to prevent the occurrence of major loss of containment incidents that are not appropriately addressed through traditional occupational health and safety procedures. This is due to the fact that many serious incidents are not simply attributable to any individual operator error. PSM strives to ensure all hazards of a process are identified and effectively managed for the lifetime of the process, regardless of changes in personnel, organization, or environment. The principles of PSM as taught in this module are based on a particular reference from the American Institute of Chemical Engineers Center for Chemical Process Safety (AIChE CCPS) [14].
The PSM learning module is a nearly 200-slide PowerPoint file, supplemented by case studies, instructor notes, and quiz questions. The module is intended to introduce the principles of process safety management to undergraduate engineering students in Canada. After completing the module, students should be able to:

- Describe the principles underlying each element of PSM.

- Recall major events which lead to the development of PSM.

- Discuss their personal responses about "greyareas" in risk management.

- Apply PSM principles to any process or facility.

\section{MODULE OUTLINE}

The PSM module consists of the sections or chapters described below.

\subsection{Introduction}

The introductory section provides an overview of PSM, and clarifies the scope. Important topics include:

- The importance of PSM in the prevention of major hazard incidents.

- Brief history and recent examples and case studies.

- Rules and regulations for PSM in Canada.

- Survey of PSM systems.

\subsection{Commitment to PSM}

PSM is a safety management system, not simply a set of tools or techniques. To be effective, all stakeholders including management and workers must be fully committed to PSM. The topics covered in this section include:

- Process safety culture

- Compliance

- Competence

- Workforce involvement

- Stakeholder outreach

\subsection{Hazard Identification and Risk Assessment}

Hazard identification and risk assessment are of central importance in PSM. They are reviewed in this section, but in-depth coverage is left to complementary learning modules

- Hazard identification \& risk management

- Knowledge management 


\subsection{Risk Management}

General principles of risk management are also covered thoroughly in a complementary learning module. This section focuses on risk management as it applies specifically to PSM. Specific topics include:

- Operating procedures

- Training \& performance

- Safe work practices

- Asset integrity \& reliability

- Contractor management

- Management of change

- Operational readiness

- Conduct of operations

- Emergency preparedness

\subsection{Enhancing PSM}

An essential element of PSM is continuous improvement of the system. Continuous improvement methods discussed in this section include:

- Incident investigation

- Auditing

- Metrics \& measurements

- Management review

\section{CASE STUdies}

The module includes detailed discussion of several important case studies, including:

- Methyl Isocyanate Release, Union Carbide, Bhopal India, 1984 [15,16]. This accident resulted in more than 3800 fatalities, more than 100,000 injuries, severe damage to area livestock and crops, long term health effects, $\$ 470$ Million compensation. Several related factors lead to this disaster.

- Hydroxylamine explosion, Concept Sciences Inc., Hanover Township, Pennsylvania, 1999 [17]. This explosion resulted in 5 deaths and 14 injuries. The main contributing factor was poor management of process knowledge.

- American Airlines Flight 191 crash, 1979 [18]. The crash resulted in 273 fatalities, and was caused by a faulty maintenance procedure. While this is not within the scope of PSM, the Safety Management Systems used to ensure safety of civilian aviation have many elements in common with PSM.

- Piper Alpha oil platform explosion, Occidental Petroleum Ltd., North Sea, 1988 [19]. This accident resulted in 167 deaths and \$1.7 Billion in property damage. The cause was a faulty maintenance procedure. Inadequate emergency response training contributed to the severity of the accident.

- Cyclohexane explosion, Napro UK, Flixborough UK, 1974 [20]. This explosion killed 28 people and damaged or destroyed 1800 buildings in the surrounding area. The cause was an unsafe modification to existing equipment. This could have been prevented by an effective change management system.

- Hot work explosion, Motiva Enterprises Refinery, Delaware, 2001 [21]. Welding sparks ignited flammable vapors, killing one worker and injuring eight others. In addition, a significant amount of sulfuric acid was released to the atmosphere. The accident was a result of several breakdowns of the process safety management system.

\section{TEST QUESTIONS AND INSTRUCTOR NOTES}

A bank of potential exam questions based on the material presented was compiled to aid instructors in the facilitation of their course. A variety of short answer, multiple choice types of questions were provided along with an example of a critical thinking exercise based on the Motiva Enterprises hot work explosion case study from the U.S. Chemical Safety and Hazard Investigation Board [21]. The case study information (without the analysis) is given to the students and a list of discussion questions is provided. Instructor notes are included in the power point presentation to provide additional details and to direct instructor towards further resources and information.

\section{COPYRIGHT}

Most images used in the module development were taken from royalty free sources such as Microsoft Clip art or freedigitalphotos.net. Other options include creative commons search on google images. Depending on how the information is being disseminated, it may be allowed under the "Educational Exception".

\section{INDUSTRY INVOLVEMENT}

The module was reviewed by several industry experts, primarily from the chemical process industry. Their valuable feedback has been incorporated into the module. 


\section{EVALUATION OF LEARNING OUTCOMES}

Preliminary feedback from Minerva and industry experts has been positive. The module has not yet been used in teaching, so no student feedback is available. Discussions are underway to implement consistent evaluation methods for all of the modules developed under this project.

\section{RECOMMENDATIONS}

At the beginning of this project, each participating university developed its own module format. There was limited collaboration between the Interns involved in module development, so several different formats emerged. It would be very helpful to merge the best ideas and develop a common module template to be used for future modules. The template should clearly define the module contents, including lecture slides, exam questions, discussion points, assignments, online quizzes, multimedia content, etc.

There should be closer collaboration between the students developing modules. In particular, module content needs to be shared at the early stages so that linkages between modules can be made clear, and so that duplication can be avoided.

\section{ACKNOWLEDGEMENTS}

This project was supported by funding from the Mitacs Accelerate program as part of an Accelerate Cluster entitled "Bridging the Gap - Health and Safety Engineering Student Teaching Modules". The overall Accelerate project was coordinated and sponsored by Minerva Safety Management Education Inc. The organization sponsor for the PSM module was Imperial Oil Ltd. We gratefully acknowledge the feedback, guidance and input of Manuel Marta (NOVA Chemicals) and Mark Stumpf (Imperial Oil).

\section{REFERENCES}

[1] Code of Ethics, Professional Engineers Ontario, http://peo.on.ca/, accessed April 7, 2014.

[2] Bilal M. Ayyub, Risk Analysis in Engineering and Economics. Boca Raton: Chapman and Hall/CRC, 2003

[3] Frank R. Spellman and Nancy E. Whiting, The handbook of safety engineering: principles and applications, Lanham, Md. : Government Institutes, 2010.
[4] Nicholas J. Bahr, System safety engineering and risk assessment: a practical approach, Washington, DC : Taylor \& Francis, c1997.

[5] Accreditation Criteria and Procedures, Canadian Engineering Accreditation Board, Canadian Council of Professional Engineers, 2012.

[6] U.S. Department of Labor. Process Safety: (OSHA 3132). s.l. : U.S. Department of Labor, 2000.

[7] Government of Canada. Canada Environmental Protection Act, 1999. Environment Canada [Online] 07 10, 2013. http://www.ec.gc.ca/lcpecepa/default.asp?lang=En\&n=E00B5BD8-1

[8] Center for Chemical Process Safety. Guideline for Management of Change for Process Safety. New York : John Wiley \& Sons, Inc, 2008.

[9] Government of Canada. Canada Occupational Health and Safety Regulations (SOR/86-304). Justice Laws Website. [Online] 07 10, 2013. http://lawslois.justice.gc.ca/eng/regulations/SOR-86-304/.

[10] Sutton Technical Books. Process Safety Management. Sutton Technical Books. [Online] 07 23, 2013. http://www.stb07.com/process-safety-management/processsafety-management-index.html.

[11] Chemistry Industry Association of Canada. Responsible Care. Chemistry Industry Association of Canada. [Online] 07 10, 2013.

http://www.canadianchemistry.ca/ResponsibleCareHome.as $\mathrm{px}$

[12] Government of Nova Scotia. The Westray Story: A predictable path to Disaster. http://novascotia.ca/lae/pubs/westray/. Accessed: June 2, 2013.

[13] Department of Justice, Government of Canada. Plain Language guide to Bill C-45. http://www.justice.gc.ca/eng/rp-pr/other-autre/c45/. Accessed: May 30, 2013.

[14] Center for Chemical Process Safety. Guidelines for Risk Based Process Safety. New Jersey : John Wiley \& Sons, 2011.

[15] Atherton, John and Gil, Fredric. Incidents that define process safety. Hoboken, NJ : John Wiley \& Sons, Inc, 2008

[16] Kletz, Trevor. What went wrong? Case histories of process plant disasters and how they could have been avoided. 5th. Oxford : Elsevier, 2009.

[17] The Explosion at Concept Sciences: Hazards of Hydroxlamine, Case Study, U.S. Chemical Safety and Hazard Investigation Board, Washington DC, No. 1999-13C-PA, March 2002.

[18] National Transportation Safety Board. Aircraft accident report: American Airlines, Inc. DC-10-10, N110AA. Chicago O'Hare International Airport Chicago, Illinois, May 25, 1979. Report 20594, 1986. 
Proc. 2014 Canadian Engineering Education Association (CEEA14) Conf.

[19] Oil \& Gas UK. Piper Alpha: Lessons Learnt, 2008.

[20] Health and Safety Executive. The Flixborough Disaster: Report of the Court of Inquiry. London : Her Majesty's Stationery Office National Archives, 1975.

[21] U.S. Chemical Safety and Hazard Investigation Board. Investigation Report. Report No. PB2002-108210. http://www.csb.gov/assets/1/19/Motiva_Final_Report.pdf Accessed Nov 9, 2013

CEEA14; Paper 76 